Bueno, B.S., Benjamim, C.V.S., and Zornberg, J.G. (2005). "Field Performance of a Full-scale Retaining Wall Reinforced with Non-woven Geotextiles." Slopes and Retaining Structures under Seismic and Static Conditions. ASCE Geotechnical Special Publication No. 140, Gabr, Bowders, Elton, and Zornberg (Editors), Austin, Texas, January (CD-ROM).

\title{
FIELD PERFORMANCE OF A FULL-SCALE RETAINING WALL REINFORCED WITH NONWOVEN GEOTEXTILES
}

\author{
Benedito S. Bueno $^{1}$, C.Vinicius S. Benjamim², and Jorge G. Zornberg ${ }^{3}$
}

\begin{abstract}
Retaining walls in Brazil have often been reinforced using nonwoven geotextiles instead of other reinforcement inclusions such as geogrids, woven geotextiles, and metallic reinforcements. This approach has several advantages such as ease of construction, expediency, and significant cost reduction. However, current lack of field data on the field performance of nonwoven geotextilereinforced structures, mainly regarding displacements, has prevented their utilization in critical structures. Observation of the behavior of full-scale structures and a further characterization of the materials are needed to gain understanding of the behavior of nonwoven geotextile-reinforced soil structures. Accordingly, a series of nonwoven geotextile-reinforced soil structures was built and instrumented to analyze their behavior. This paper presents the results of a full-scale field monitoring program and associated finite element analyses conducted for a nonwoven geotextilereinforced soil wall. The results show that current design methods provide conservative evaluation of the overall stability of the structure. The results of the numerical simulation indicate that FEM is a useful tool to predict the response of structures reinforced with geosynthetics. Monitoring results were found to be in agreement with those obtained in the numerical simulation.
\end{abstract}

\section{INTRODUCTION}

The use of nonwoven geotextiles in reinforced retaining walls presents several advantages in relation to the use of other reinforcement inclusions. This includes ease of construction, expediency, possible lateral drainage, and significant reduction in costs. However, despite these important advantages related to the utilization of nonwoven geotextiles as reinforcement, most retaining walls around the world use more conventional solutions such as geogrids, metallic reinforcements or woven geotextiles. The lack of field monitoring data regarding the actual behavior of nonwoven geotextile-reinforced soil structures, mainly in terms of displacements, has prevented a broader use of this reinforced soil technology.

When using polypropylene geotextiles, the issue of creep has been an additional concern that may have prevented a widespread use of geotextiles as reinforcement inclusions. The lack of creep data for PP geotextile has often led to the use of creep reduction factors as high as 7 . The use of such large creep reduction factors and the comparatively lower tensile strength of nonwoven geotextiles has relegated the use of nonwoven geotextiles to small structures subjected to minor surcharges. Several aspects related to the behavior of these structures still needs further insight, such as the stress distribution within the backfill, the deformability of the reinforcement materials under the confinement of soil, and the actual failure mechanisms.

The difficulty in predicting the behavior of this type of structure using current design methods has been reported by many authors. A good example was reported by Wu (1992), who requested predictions on the behavior of a highly instrumented reinforced soil structure. The predicted results showed a significant scatter when compared to the monitored response of the prototype. Many factors have contributed to such discrepancy. Among them, the contribution of suction to the shear strength of the soil, the increase in stiffness of reinforcements under the confinement of soil, and the contribution of soil arching to the stability of the structure. In summary, field observation of the

\footnotetext{
${ }^{1}$ Professor, University of Sao Paulo, Sao Carlos, Brazil

${ }^{2}$ Graduate Student, University of Sao Paulo, Sao Carlos, Brazil

${ }^{3}$ Assistant Professor, University of Texas at Austin, US
} 
GSP 140 Slopes and Retaining Structures under Seismic and Static Conditions

behavior of prototypes and suitable characterization of the involved materials are still necessary. However, the instrumentation of field prototypes is expensive, and the collected field data may address only limited aspects governing the overall behavior of these structures.

To address these shortcomings, a series of geotextile-reinforced soil wall was built and instrumented in the vicinity of the University of Sao Paulo at Sao Carlos. This paper presents preliminary information collected from one of the prototypes constructed as part of the field monitoring program. In addition, finite element analyses are conducted to gain better understanding on the behavior of retaining walls reinforced using nonwoven geotextiles.

\section{MATERIAL AND METHODS \\ Overview}

The prototype was constructed using wrap-around facing. To provide a plane strain condition, the geometry of the wall was defined with $4 \mathrm{~m}$ wide, $4 \mathrm{~m}$ high and $4 \mathrm{~m}$ long Prototypes were built in pairs (two walls were placed in a row back-to-back) and were confined laterally by two longitudinal wooden walls. Also, plastic greased membranes were placed over the wooden walls in order to minimize lateral friction between the soil and the wood structure. Figure 1 shows a picture of the

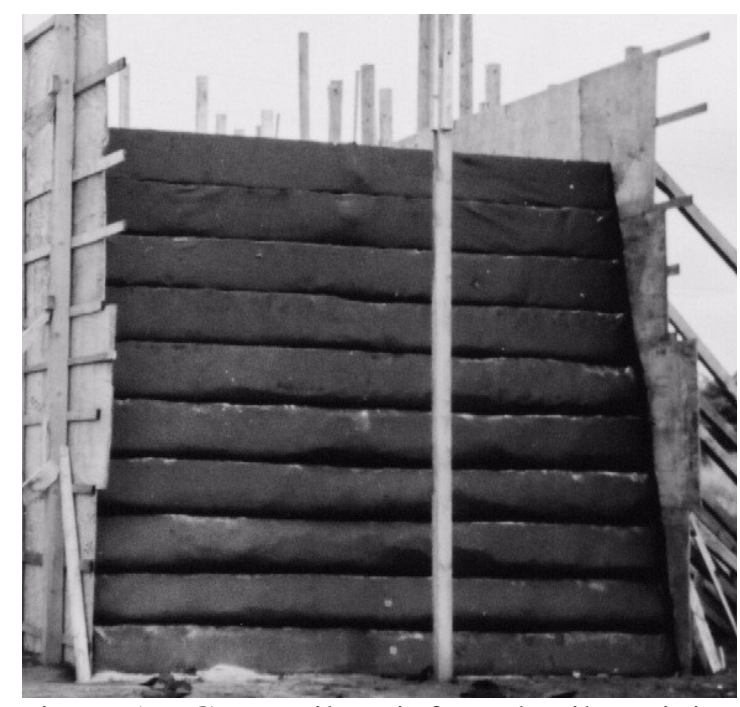

Figure 1 - Geotextile-reinforced soil retaining wallprototype

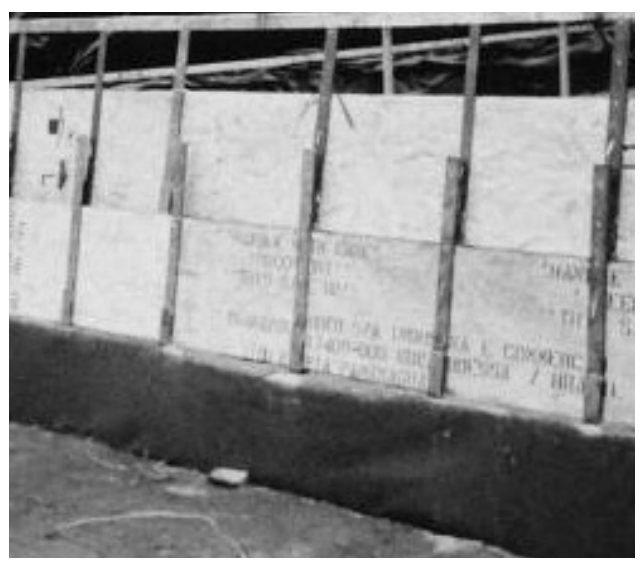

Figure 2 -Wrap system prototype.

The wall was built using 10 geotextile layers placed with $0.40 \mathrm{~m}$ vertical spacing. The structure was constructed atop of a $0.40 \mathrm{~m}$ reinforced base layer of dense sand to increase its external stability. The wrap-around system was assembled using metallic supports and wood boards, for a final angle of $78^{\circ}$ with the vertical (face slope of 1:5), as shown in Figure 2. The backfill soil was compacted using a vibratory plate (Figure 3 ).

\section{Material Characteristics}

A fine to medium well-graded sand was used to construct the backfill. Its grain size distribution is presented in Figure 4. The shear strength parameters of the soil were obtained from both direct shear and consolidated-drained triaxial tests, using the same relative density and water content found in the field. The results from these tests are listed in Table 1.

A shork fiber needle punched polyester nonwoven geotextile was chosen as the soil reinforcement. No seams were used during placement of the reinforcements. The main characteristics of the geotextile are:

- Mass per unit area: $204.40 \mathrm{~g} / \mathrm{m}^{2}$

- Thickness: $1.26 \mathrm{~mm}$

- Ultimate load:8.41 kN/m

- Ultimate elongation:89.81\%

- Elasticity Modulus: 13.00 kN/m 
GSP 140 Slopes and Retaining Structures under Seismic and Static Conditions

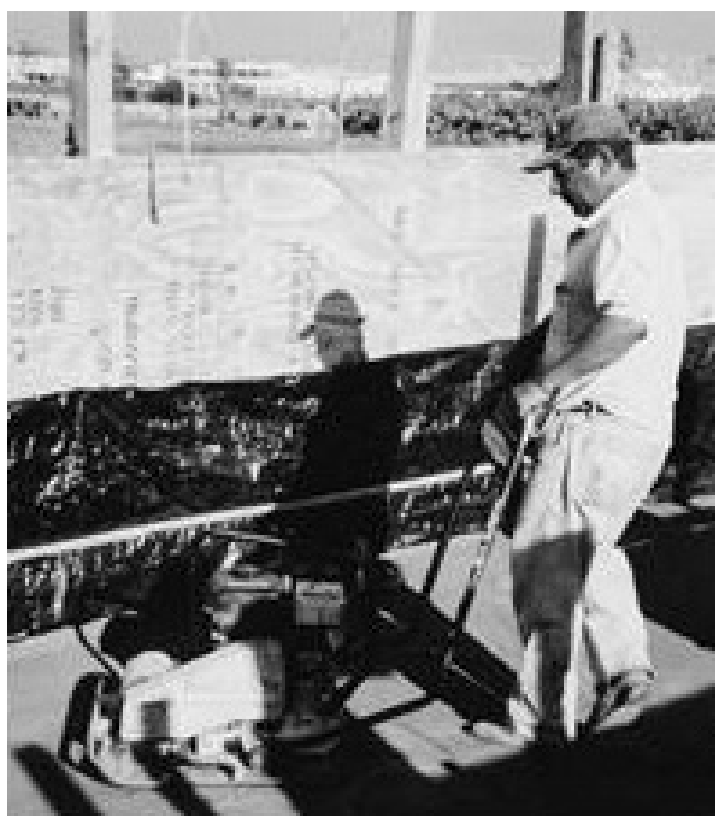

Figure 3 - Vibratory plate

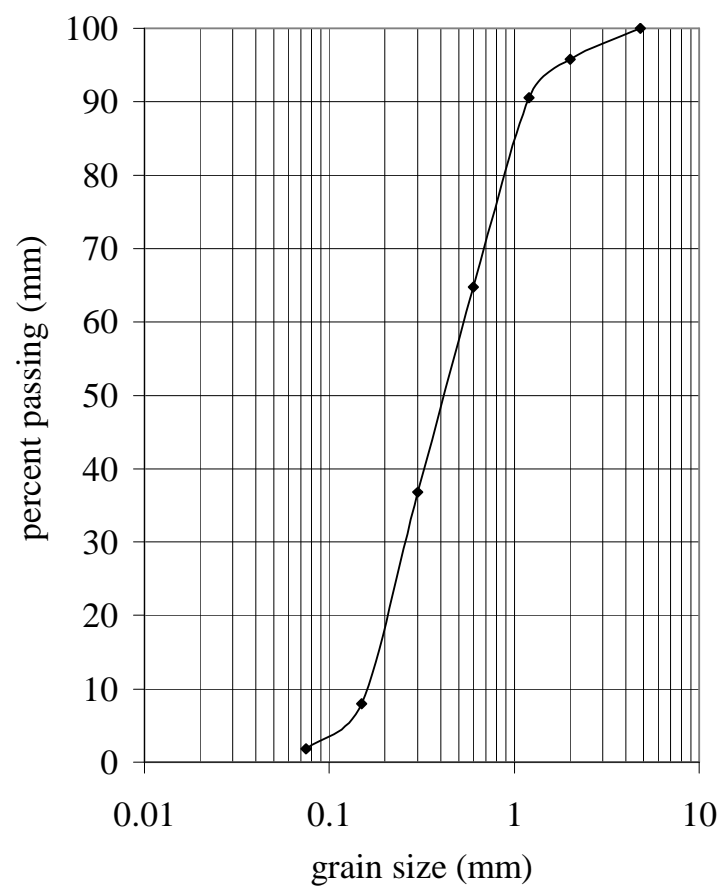

Figure 4 - Grain size distribution

Table 1 - Soil shear strength parameters

\begin{tabular}{|c|c|c|}
\cline { 2 - 3 } \multicolumn{1}{c|}{} & From triaxial tests & From direct shear tests \\
\hline Cohesion & $16 \mathrm{kPa}$ & $15 \mathrm{kPa}$ \\
\hline Friction angle & $33^{\circ}$ & $32^{\circ}$ \\
\hline
\end{tabular}

\section{Instrumentation}

Three different aspects of the wall behavior were evaluated using field instrumentation during and after construction. The instrumentation layout is shown in Figure 5. The instrumentation plan included: (a) surveying of face displacements; (b) vertical magnetic extensometers, and (c) tell tails for measurement of the horizontal displacements within the reinforcements. These instruments are described next.

Surveying of face displacements: The displacements of the wall face were measured during and after construction by quantifying the distance of points placed in the center of each layer, to a fixed reference point. The resolution of these measurements was $1 \mathrm{~mm}$.

Vertical magnetic extensometers: The magnetic extensometers were designed and constructed as part of this study in order to measure the vertical settlements of the backfill. The extensometer is composed of magnetic plates attached to PVC pipes. The magnets were attached to the center of each plate to register the vertical position of a probe. Displacements were measured by introducing an aluminum probe that has a reed switch installed in its tip. When the probe approaches the magnet, an electric circuit closes and activates a sound indicator in a voltmeter connected to the sensor. Measurements were taken made when the sound indicator starts and stops, which correspond to the top and bottom faces of the magnet. The exact position of the magnet is then calculated as the average value of these two points. The resolution of this instrument is $1 \mathrm{~mm}$ (Figure 6).

Tell-tails: The internal displacements within the reinforcements and the face of the wall were measured using tell-tails. They consist of $0.35 \mathrm{~mm}$ diameter stainless steel inextensible wires, running within nylon tubes used to reduce friction and protect the wires. One end of the tell-tales is 
GSP 140 Slopes and Retaining Structures under Seismic and Static Conditions

fixed to the geotextile and the other is at a free end, located in a shaft behind the wall, which is used to measure the displacements (Figure 7). Measurements were made using a digital caliper with a resolution of $0.01 \mathrm{~mm}$ (Figure 8).

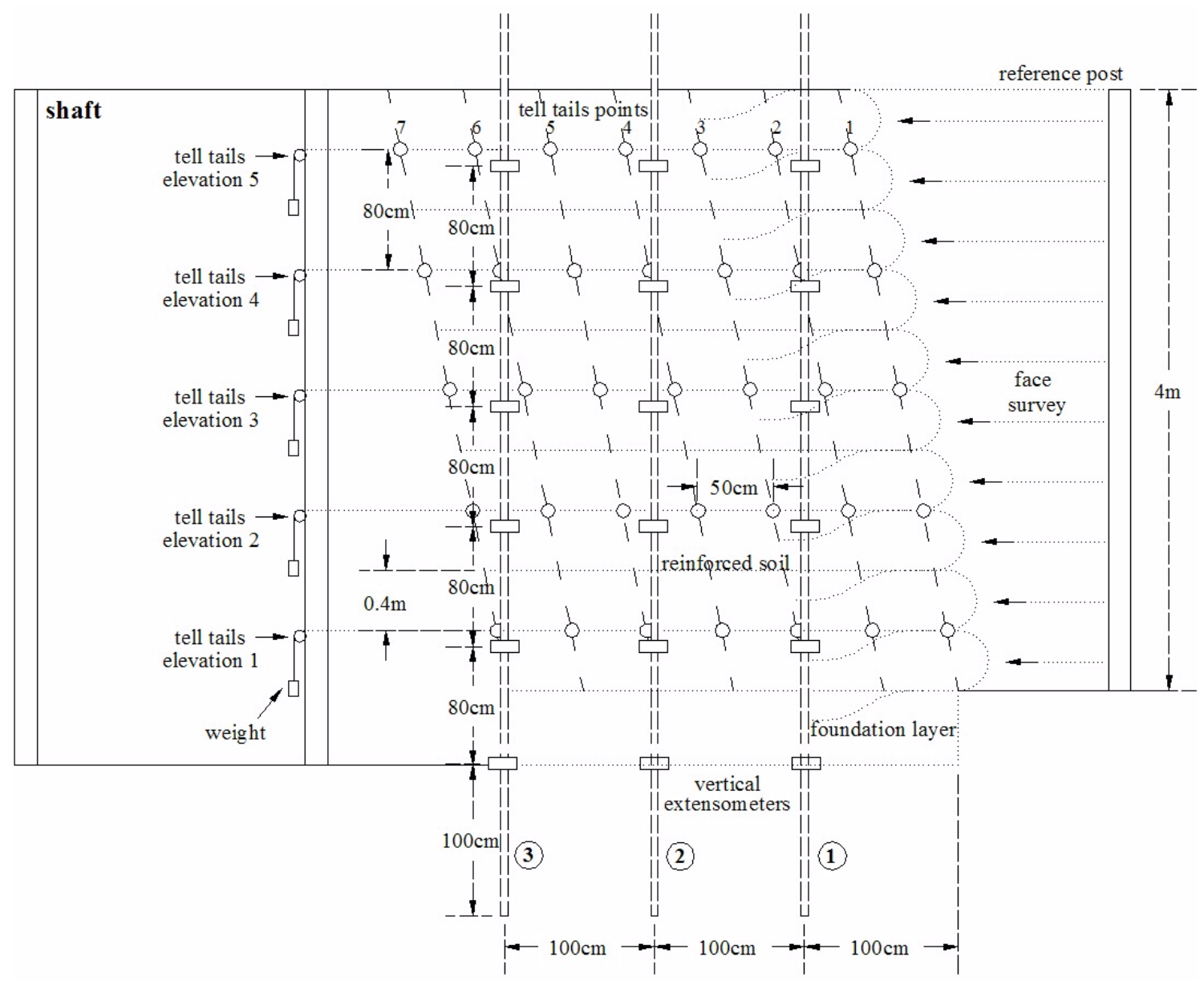

Figure 5 - Layout of instrumentation in prototype wall

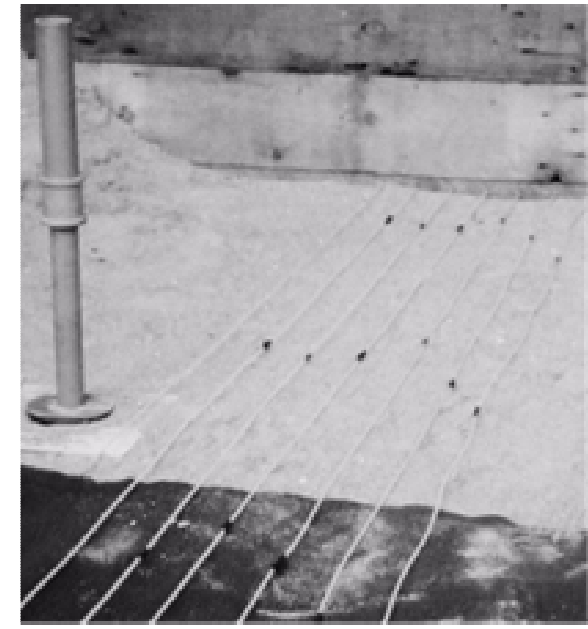

Figure 6 - Vertical extensometer pipe (left) and tell-tailnylon pipes (right)

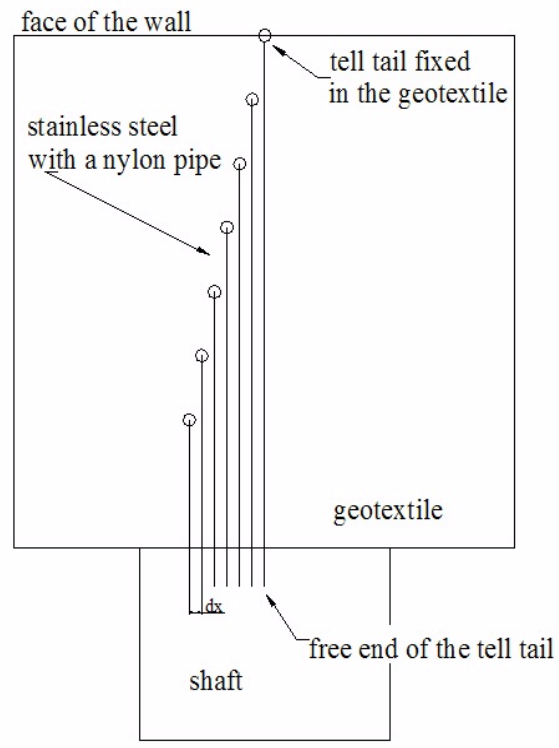

Figure 7 - Layout of tell-tails in a reinforcement layer 


\section{PRELIMINARY RESULTS}

Prototype face and internal displacements were measured during and after construction of the wall. Some of the field monitoring collected in this wall results are presented below.

\section{Vertical displacements within the backfill}

The vertical displacements within the backfill were very small. The vertical strains calculated from the displacements were below $1 \%$. Figures 9, 10 and 11 present a central cross section of the wall with the calculated vertical strains. The results shown in Figures 9, 10 and 11 indicate that largest vertical strains occurred towards the base of the structure. The strains decrease with the height of the wall and are negligible in the top layer. The largest vertical strains occurred close to the face. That is, vertical strains were larger within the active wedge.

\section{Horizontal strains within the reinforcements}

The horizontal reinforcement strains were also small. In general, the largest horizontal strains occurred close to the face, approximately at mid-height of the wall. Figures 12, 13 and 14 present the horizontal reinforcement strains. The

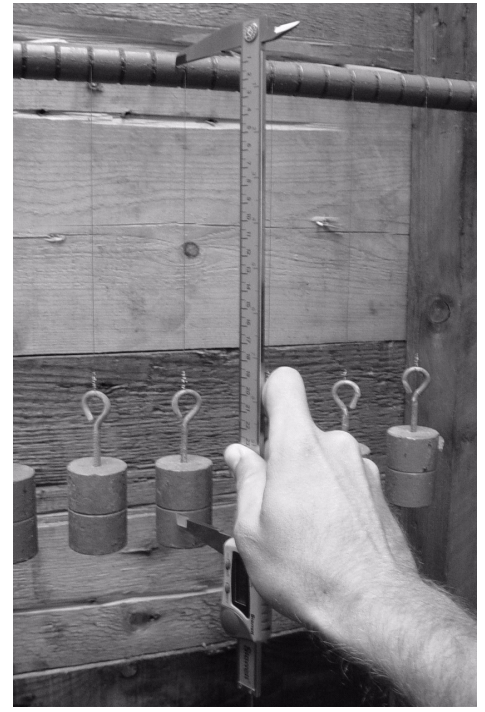

Figure 8 - Free end of the tell-tail horizontal displacements close to the face occurred mainly during construction, as the accommodation of the soil particles was observed after removing the wooden face supports. After construction, these displacements continued to increase, indicating the development of an active zone (Figure 15).

The walls underwent a rainy season, when a decrease in soil suction and an increase in the weight of the wedge may have occurred. However creep displacement did not occurred as timedependent displacements stopped after some months. A possible reason for the small magnitude of the recorded post-construction horizontal displacements is the polymer type (polyester). Another reason for the small strains of the prototype is the drainage control and therefore the permanence of soil suction throughout the year.

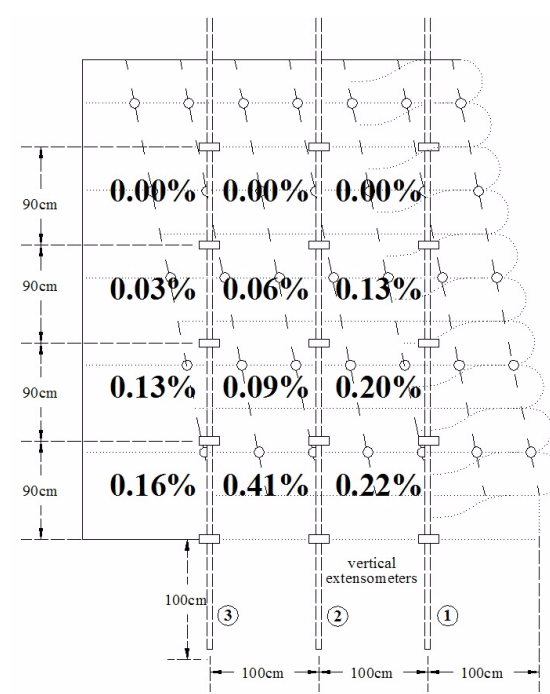

Figure 9 - Vertical strains at the end of construction $(\%)$

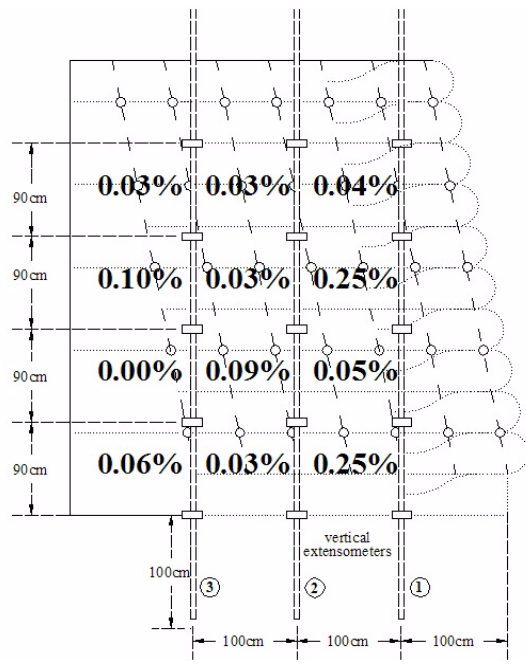

Figure 10 - Vertical strains after construction

(\%) 
GSP 140 Slopes and Retaining Structures under Seismic and Static Conditions

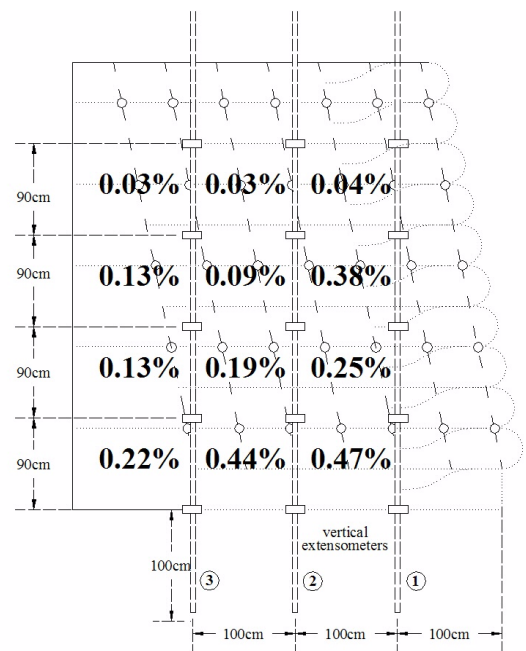

Figure 11 - Total vertical strains $(\%)$

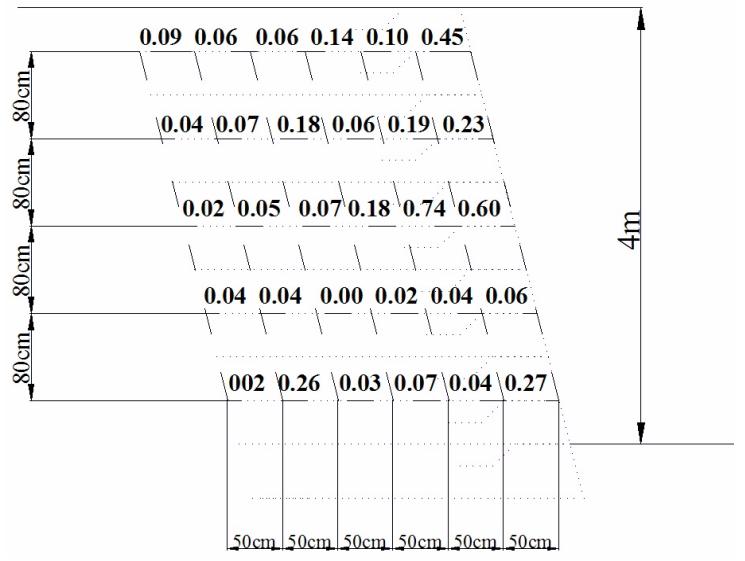

Figure 13 - Reinforcement strains after the construction, creep (\%)

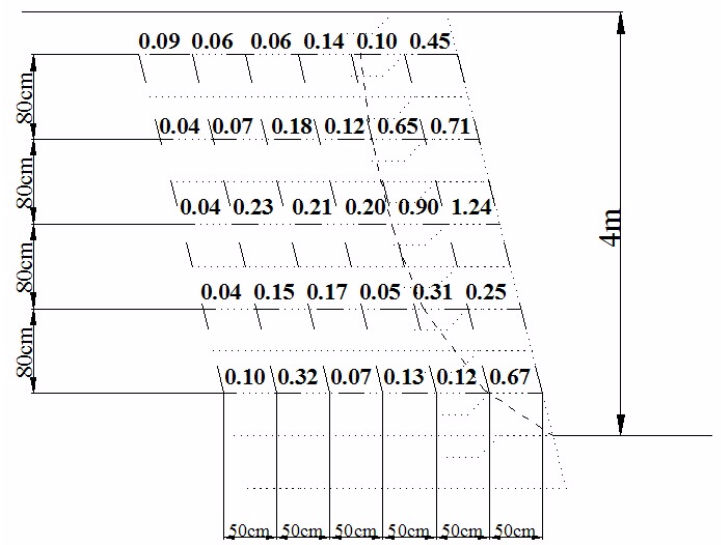

Figure 15 - Indication of the slip surface

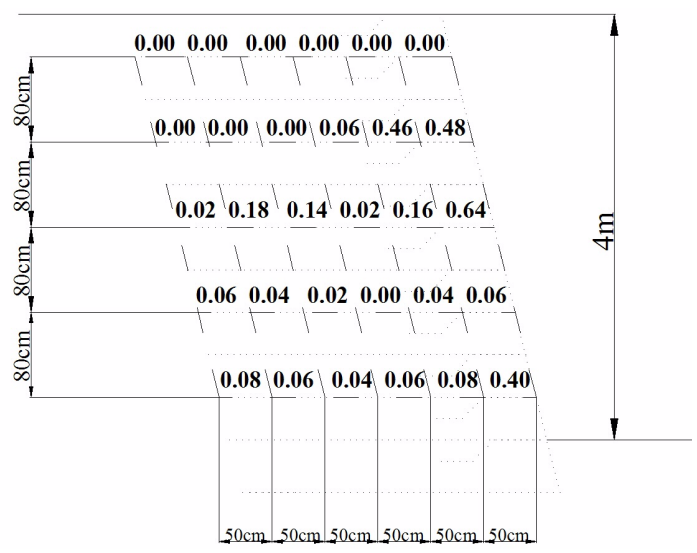

Figure 12 - Reinforcement strains at the end of the construction (\%)

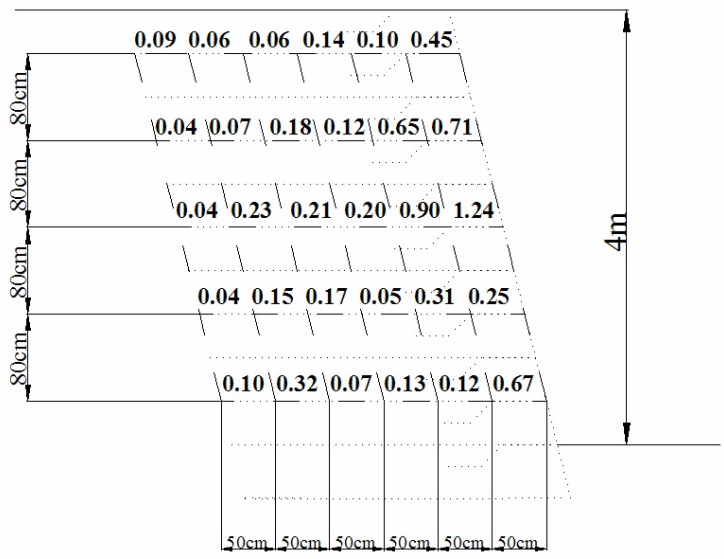

Figure 14 - Total reinforcement strains (\%)

\section{Face displacements}

The horizontal displacements measured at the face by surveying were much larger than the displacement measured by the tell-tails. However, these displacements are mainly the result of accommodation of each layer during construction, since this external measurement was made in the middle of each layer.

It is difficult to establish correlations between the displacements at the face measured using surveying and tell-tails, but it is clear that the largest displacements of the face are in the middle of the wall, as shown by both aproaches. Figures 16, 17 and 18 show the face displacements. The front wall face was designed to reach an inclination $1 \mathrm{H}: 5 \mathrm{~V}\left(78^{\circ}\right)$. However, due to accommodation during construction, the final face slope was approximately $1 \mathrm{H}: 4 \mathrm{~V}\left(76^{\circ}\right)$. 


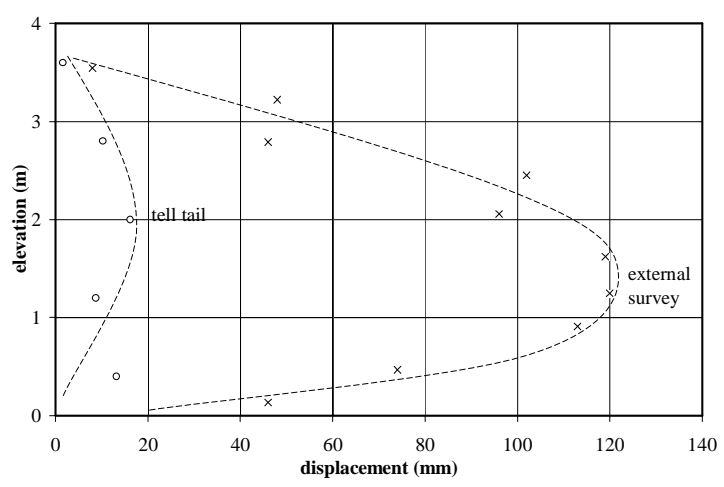

Figure 16 - Vertical displacement of the face

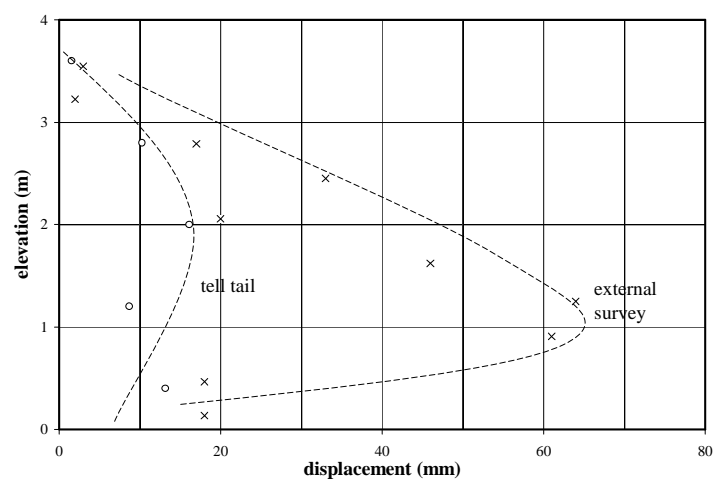

Figure 17 - Horizontal displacement of the face

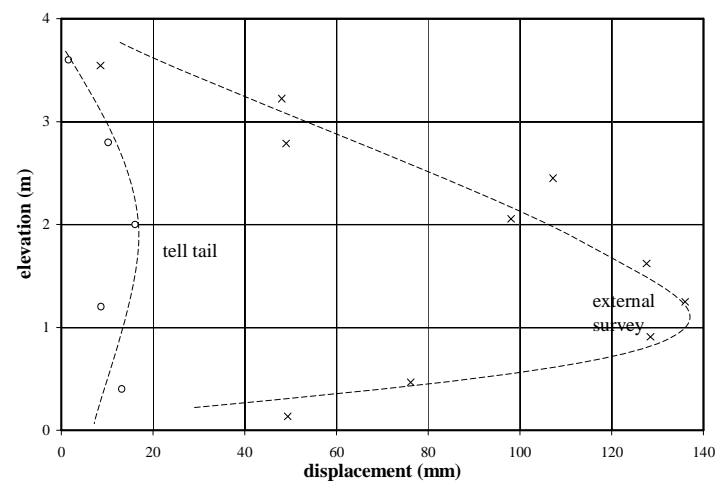

Figure 18 - Total displacement of the face

\section{Vertical strain of the backfill}

The vertical strains obtained in the numerical simulations were small, which is consistent with the actual strains obtained from monitoring of the reinforced backfill. The Figures 20 and 21 shows the results of the numerical analyses.

\section{Reinforcement strain}

The horizontal displacements obtained from the numerical simulation compare well with the results collected from the prototype instrumentation (Figures 22 and 23). Consistent with the results obtained from data of prototype instrumentation, the reinforcement strains obtained from numerical simulation were very small. While small, the strains

\section{NUMERICAL SIMULATIONS}

Numerical simulations were performed in order to obtain additional information on the behavior of the prototype wall and to allow comparisons with instrumentation data. The simulations were performed using Plaxis (version 7.12). Figure 19 shows the mesh used in this study. The finite element method technique allows parametric evaluations to explore the effect of the properties of the different wall components (e.g., soil types, inclusions, layout, inclusion stiffness) on the overall wall behavior.

The parameters adopted for the soil can be summarized as follows:

- Model: hardening soil model

- Type of material: drainded

- Young's modulus: $5 \times 10^{4} \mathrm{kN} / \mathrm{m}^{2}$

- Specific weight of the soil: $18 \mathrm{~km} / \mathrm{m}^{3}$

- Cohesion: $15 \mathrm{kN} / \mathrm{m}^{2}$

- Friction angle: $32^{\circ}$

- Dilantancy: $14^{\circ}$

The parameters for the nonwoven geotextile reinforcements can be summarized as follows:

- Elastict y modulus: $13 \mathrm{kN} / \mathrm{m}$

- Interface soil-geosynthetic: rigid

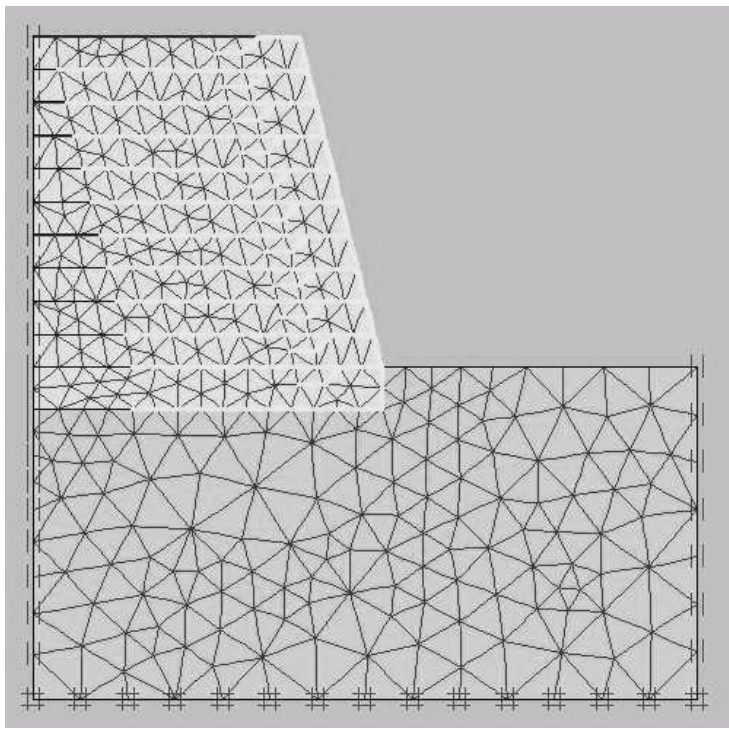

Figure 19 - Mesh of reinforced soil 
GSP 140 Slopes and Retaining Structures under Seismic and Static Conditions

show a small evidence of the development of a slip surface starting at the foot of the slope and propagating into the soil mass.

\section{Face displacements}

The displacements of the face obtained from the numerical simulation do not compare well with the field results obtained using surveying. However, the results are consistent with those measured by the tell-tails (Figures 24 and 25). The differences can be attributed to the fact that the numerical simulation does not consider the effect of compaction on the face displacement of each layer. Also, an updated mesh method was used in the simulation, which has resulted in larger displacements in the top of the structure.

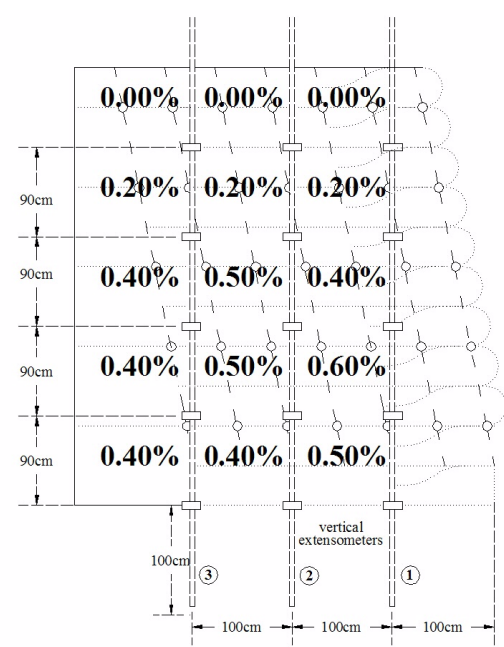

Figure 20 - Vertical strains obtained in the numerical simulation $(\%)$

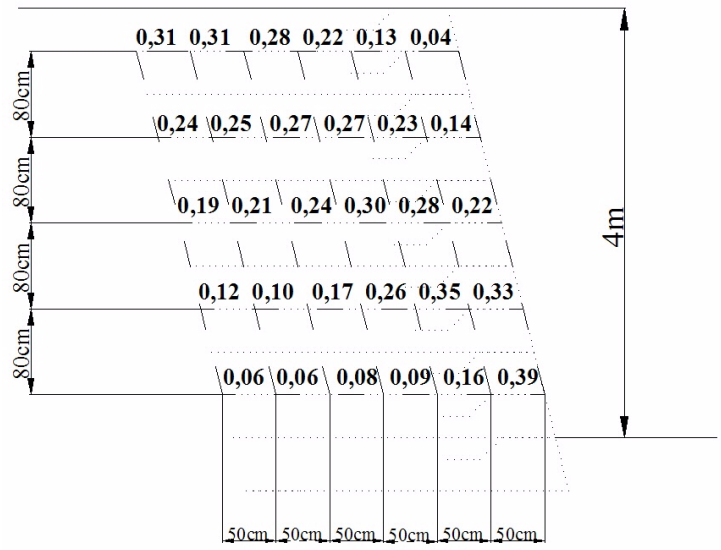

Figure 22 - Reinforcement strains obtained in the numerical simulation $(\%)$

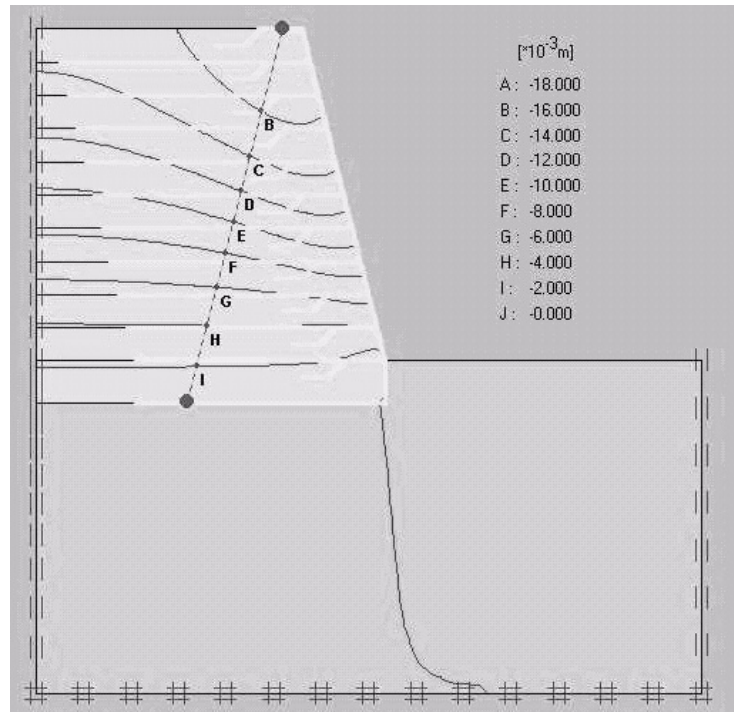

Figure 21 - Vertical displacement of the backfill (mm)

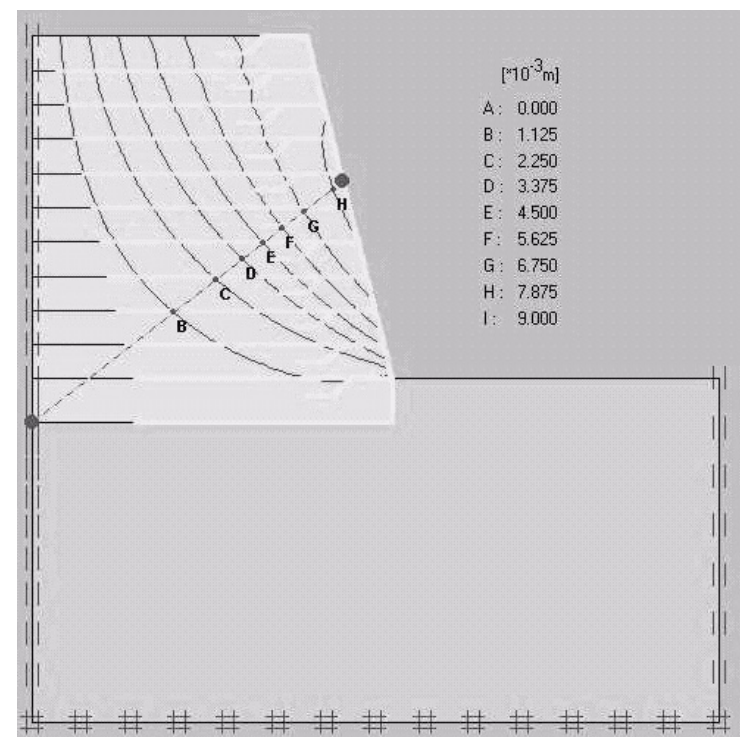

Figure 23 - Horizontal displacement of the backfill (mm) 


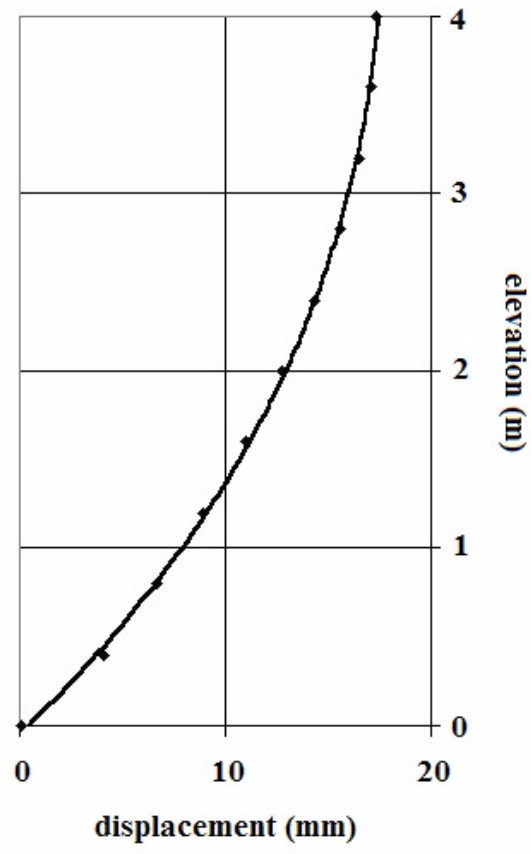

Figure 24 - Vertical displacement of the face

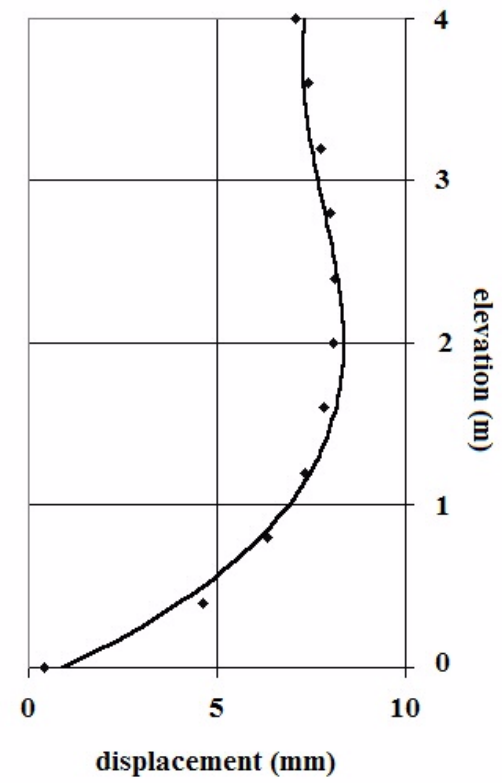

Figure 25 - Horizontal displacement of the face

\section{CONCLUSIONS}

A full-scale prototype of a nonwoven geotextile-reinforced wall was constructed to address technical shortcomings present in the state of practice for reinforced soil structures.

The vertical strains obtained from vertical extensometers were very small, with the larger strains within the active wedge. The horizontal reinforcement strains were also very small. In general, the largest horizontal strains occurred towards the face of the structure, approximately at mid-height of the wall. Such displacements were mainly caused during construction, induced by soil accommodation observed after removing the wooden supports. The horizontal displacements of the face measured by surveying were larger than those measured by tell-tails. Even thought a decrease in shearstrength was anticipated during the rainy season because of an expected loss in soil suction, time-dependent displacements were negligible a couple of months after construction. Overall, the results of the monitoring program suggest that current design procedures are conservative, as the displacements are smaller than expected.

The results of numerical simulations showed that the finite element method is a useful tool to predict the behavior of structures reinforced with geosynthetics, as the displacements predicted by numerical simulations are in good agreement with the monitored results.

\section{AKNOWLEDGEMENTS}

This research received financial support of Ober S.A, FAPESP and CAPES. Support received by the third author by the National Science Foundation under Grant No. CMS-0070248 is also acknowledged.

\section{REFERENCES}

Associação Brasileira de Normas Técnicas (1984). "NBR 7181 - Análise Granulométrica".

Mitchell, J. K., Villet, W. C. B. (1987). "Reinforcement of earth slopes and embankments" National Cooperative Higway Research Program Report. n. 290.

Wu, J.T.H. (1992). "Geosynthetic-Reinforced Soil Retaining Walls" Proceedings of the International Symposium on Geosynthetic-Reinforced Soil Retaining Walls. Denver, Colorado. 